\section{PARTICLE SIZE ANALYSIS}

$P$ ARTICULATE material is a general descriptive title for the many forms of matter existing in a state of sub-division into discrete particles. Such materials play an important part in almost all human activities, either as dust particles formed by natural agencies, or as powders produced by the artificial reduction in size of larger fragments of material. Dust is always present in the atmosphere, and though generally regarded as a nuisance, also fulfils useful purposes; but when present in excessive quantities it becomes a menace to health, and much active research is in progress to minimize the harmful effects of dust in mining and industrial atmospheres. Artificially ground powders are of the greatest importance to industry ; sometimes their production is the main objective, as in the manufacture of Portland cement or pigments, and fine grinding of immense tonnages is an essential stage in the reduction of metallic ores. The building industry uses large quantities of materials in powdered or granular form, and a knowledge of the size analyses of these is essential. Agriculture and civil engineering are concerned with problems such as soil erosion, silt deposition and the foundations of buildings, for which data on the size characteristics of sedimentary deposits are needed. Thus there can be few manufacturing processes which are not dependent upon the use of powdered materials at some stage, and though the quantities involved may be smaller than in the industries mentioned above, the monetary value may be high, as for example in the fabrication of parts from motal powders.

Empirical methods of examination combined with the results of experience have in the past sufficed to determine the quality and the suitability of a powder for a particular industrial purpose, but for the last twenty years considerable attention has been given to methods of particle-size determination. During this period the literature on the subject has grown rapidly in volume; indeed this abundance is somewhat confasing to those commencing a study of methods of particle-size analysis.

A conference was held on February 4 by the Institution of Chemical Engineers and the Society of Chemical Industry (Road and Building Materials Section) with the object of clarifying this situation and summarizing the results of recent researches. The interest in the subject was even greater than expected, for out of an attendance of about 350 persons, quite a large number were unfortunately unable to gain admission to the meeting hall. The conference was divided into morning and afternoon sessions; at the morning session there were six papers dealing with methods of size analysis, and at the afternoon session five papers dealing with industrial applications of sizing analyses, all presented in abstract*. The authors were selected from research workers in Government or Government-aided research laboratories, universities and industrial research departments particularly concerned in the subject. Although elearly impossible to cover every aspect, the

* The authors of papers were as follows :

Methods of Measurement: C. N. Davies (Industrial Health Research Board, Medical Research Council); Dr. S. J. Gregg (University College, Exeter); Dr. H. Heywood (Imperial College of Science and Technology, London); Dr. F.M. Lea and R. W. Nurse (Building Research Station) Dr. D. G. Skinner and Dr. S. Boas-Traube (British Colliery Owners Research Association);

mental Station, Porton).

Industrial Applications: Dr. A. C. C. Newman (Paint Research Station); Dr. R. K. Schofleld and Dr. E. W. Russell (Rothamsted Experimental Station); Dr. M. L. Smith (Philips Lamps, Ltd.); F. W. Bernhardt (Dussek Bitumen and Taroleum, Ltd.). papers presented a cross-section of recent developments in particle-size measurement and typical industrial applications. The chairman of the morning session was Mr. Hugh Griffiths, president of the Institution of Chemical Engineers, and the discussion was opened by Dr. Idris Jones, director general of research for the National Coal Board. Dr. Jones directed attention to the importance of particle-size measurements in the coal industry, and emphasized the need for a study of dust-sampling methods. $\mathrm{He}$ especially stressed the need for developing a rapid method of size analysis, otherwise there were long delays in applying research to urgent industrial problems.

Dr. L. H. Lampitt, president of the Society of Chemical Industry, took the chair at the afternoon session, and opened the discussion by directing attention to the many applications of particle-size analysis in the food industry. Some thirty speakers contributed to the discussion during the day ; many of the comments referred to technical points of detail which will be very helpful in developing research on the subject; but the problem of simplifying the situation for the newcomer to this field of study was scarcely touched. There appear to be three methods that are most promising for the routine measurement of the fineness or state of sub-division of a powdered material. These are the adsorption method of determ. ining surface area, the permeability to fluid flow as a measure of external surface area, and the light. extinction or turbidimeter method of determining particle-size distribution and surface area. The three methods measure different properties of the powder, however, and several speakers directed attention to the need for a co-operative research which would delineate the characteristics of these methods of examination and enable some correlation of the results to be made. This could be done by a comprehensive series of tests on materials of particular importance to industry, and is clearly a subject for future research. The problem of standardization was not dealt with specifically in the discussion ; although the British Standards Institution is now engaged in the preparation of standards for the size analysis of certain materials, an extension to cover powdered materials in general would be of great benefit to industrial research workers.

Prominence was given in several of the papers to the definition of terms, with particular reference to aggregates of particles. Much research on the measurement of particle size has been conducted on the assumption that the particles are individual or discrete entities of crystalline nature; indeed, the dispersal of a sample of powder into such a state is one of the problems of analysis. In many practical applications of powdered materials, however, the individual particles are often clustered together in aggregates known as 'working' or 'operational units' which are not physically constant, for the state of aggregation depends on the treatment to which the powder is subjected; for example, it will be different in the dry and wet states, though other factors exert considerable influence. Future research must be devoted to a study of these aggregates and to methods of measurement which indicate the size of these as well as of the discrete particles composing them.

The determination of particle-size analysis is an essential preliminary to the study of many industrial problems involving particulate materials, and much research has been hindered or even wasted by insufficient or incorrect knowledge of this factor. Thus, 
research on the theory of grinding or on the efficiency of commercial dust filters cannot progress without a knowledge of the size analysis of the materials concerned; and fundamental research on these and many other subjects is impossible until consistent and rapid methods of size analysis have been developed.

This conference was the first of a public nature to be held in Great Britain to consider the properties of powdered materials, and marks an important advance in the study of this branch of applied science. The complete set of papers and the ensuing discussion, both at the meeting and in writing, should become a valuable source of reference on the subject for many years.

HAROLD HeYWOOD

\section{SOCIETY FOR EXPERIMENTAL BIOLOGY \\ CONFERENCE IN UTRECHT}

$\mathbf{A}^{\mathrm{T}}$ $T$ the suggestion of Prof. G. J. van Oordt, the Society for Experimental Biology was invited by the botanists and zoologists of the University of Utrecht to hold a conference there during April 11-14. This was a memorable event in the history of the Society, being the first occasion on which a meeting had been held outside Great Britain. Utrecht and its ancient University have been for long associated with the struggle for the freedom of thought in Europe, and, after the recent relief from a period of intellectual suppression, it was a peculiarly happy environment for scientific discussion.

The response to the invitation was much greater than was expected, and the conference was attended by more than eighty members of the Society and about forty biologists from Holland, as well as a few from Belgium. As usual, there were separate botanical and zoological sessions, one in the Botanical Laboratory which, with the adjacent Botanical Gardens, is directed by Prof. V. J. Koningsberger, the other in the Zoological Laboratory, the two main sections of which, devoted to experimental embryology and to endocrinology, are under the direction of Prof. C. P. Raven and Prof. G. J. van Oordt respectively.

Some fifty-five papers were read which covered a wide field, though many centred around subjects upon which active research is now in progress in Holland-phytohormones, absorption of substances by plants, growth and differentiation of animal tissues, and comparative physiology. During a discussion on the possible influence of phytohormones on the fine molecular structure of the plasma membrane, we learnt that the deficiencies in Holland's war-time diet had prevented the secretion into the urine of auxin- $a$, for which the botanists at Utrecht had therefore been compelled to substitute indolyl acetic acid in their experiments on plant growth. Among other interesting subjects discussed in the Botanical Section were the absorption and transport of ions and the influence on this of illumination, the structure of the cell wall, apogamy in ferns and a quantum interpretation of certain data on phototropism. The Zoological Section devoted a morning to tissue differentiation, beginning with the development of bone and widening out into a gerreral discus. sion on cellular differentiation. Another set of papers on neurophysiology, mostly of vertebrates, but including one on sea anemones, also provided material for good discussion. The rest of the papers were not so closely interrelated, but it was generally agreed that the meetings were stimulating and led afterwards to inuch informal discussion of these and other subjects of mutual interest to Dutch and British biologists. All communications were read in English and, to our great admiration, the proceedings were in no way hampered by the fact that our hosts were speaking a language in which they have had little practice in recent years.

During the afternoon of April 12, four of the University's Institutes showed demonstrations illustrating their current research. In the Botanical Institute were demonstrations of microdissection, of micro-chemical methods and of hormone test technique. In the Physical Laboratory (director, Prof. J. W. M. Milatz) is a biophysical research group working chiefly on problems connected with micro-organisms and photosynthesis, and here we were also privileged to see one of the few surviving original van Leeuwenhoek microscopes in an interesting demonstration of the history of microscopy. Work on experimental embryology and endocrinology was shown in the Zoological Laboratory; and in the Institute of Comparative Physiology, built in 1936 for the late Prof. Jordan with the aid of the Rockefeller Foundation, the research illustrated was mainly concerned with digestion and with the physiology of invertebrate muscle. This was the only occasion on which mem. bers of the Society experienced anything approach. ing disappointment as, owing to the excellence, number and geographical dispersion of the demonstra. tions, many were unable to see as much as they would have liked, though this was unavoidable.

The general organisation of the Conference and of its subsidiary functions was excellent, and for this we have to thank the local secretary, Mr. J. C. van de Kamer. In the evening of April 11 the delegates were received in the Central Museum by Dr. G. A. W. ter Pelkwijk, Lord Mayor of Utrecht and curator of the University, and by the director of the Museum, Jonkvr. Dr. C. H. de Jonge; and on the following evening there was a reception in the University by the president-curator, Jhr. Dr. L. H. Bosch Ridder van Rosenthal, followed by a chamber music concert by "The Society for Old Music" of works by Purcell and de Fesch. On Sunday, April 13, we were the guests of the Dutch Government in an excursion through North Holland to the Zuider Zee Dyke, and one of the chief engineers, Jr. Volker, and Mr. Botermans from the Governmental Department of Information, kindly acted as guides and explained some of the hydrological and biological problems connected with land reclamation.

By the generous invitation of one of the students' committees of the University of Utrecht, members of the conference were permitted to use as meeting-places and restaurants on $\theta$ of the clubs of the Utrechtsch Studentencorps, and a club of the Utrechtsch Vrouwelyke Studenten Vereeniging. This not only added greatly to the comfort and enjoyment of the proceedings, but also enabled us to understand how the Dutch have successfully solved the problem of a traditional corporate life in a non-residential university. But it must be especially emphasized that nearly all the eighty members of the conference were lodged and entertained in the homes of the University staff and of other professional people in the neighbourhood. In the present very difficult circumstances this is hospitality indeed; and one of the most significant features of the conference was the openhearted demonstration of personal and informal 